\title{
A Fuzzy-based Sustainability Assessment Approach for Promoting Sustainable Urban Mobility
}

\author{
Jyh-Rong Chou \\ Department of Creative Product Design
}

\author{
I-Shou University \\ Kaohsiung City 84001, Taiwan, ROC \\ E-mail address: jrchou@isu.edu.tw
}

\begin{abstract}
Sustainable urban mobility refers to the broad subject of urban transport that is sustainable in the senses of economic, social, and environmental perspectives by meeting the needs of both current and future generations in an efficient manner. This paper presents a fuzzy-based sustainability assessment approach for the promotion of sustainable urban mobility. It can be used to assist decision makers in assessing mobility alternatives and enabling urban planners to make necessary adjustments of more sustainable urban mobility. In the proposed approach, a hierarchical structure of sustainability indicators was developed as decision criteria for the sustainability assessment. Fuzzy measures based on Gaussian fuzzy numbers associated with 7-point linguistic terms were used to aggregate the indicators into a performance index. A case study concerning the sustainability assessment of alternatives for urban transportation systems was conducted. A modified shared-use vehicle system was further proposed for supporting the implementation of the case study.
\end{abstract}

Keywords-Sustainability assessmen;, Sustainability indicator; Fuzzy measure; Performance index; Sustainable urban mobility; Case study

\section{INTRODUCTION}

Automotive industry has risen incredibly to provide mobility for public transportation, logistics, and personal demands since the early 20th century, and massive road infrastructures and motorized vehicles have transformed the scenery in cities around the world. In the meanwhile, the dominant dependency of urban mobility has increased the burden on the society and environment, including growing traffic congestion, air quality degradation, and increased energy consumption. Cities around the world are facing the challenge of reducing greenhouse gas emissions and promoting urban sustainability. Urban sustainable development can be expressed as achieving a balance between the development of the urban areas and protection of the environment with a perspective to equity in income, employment, shelter, basic services, social infrastructure and transportation in the urban areas [1]. Although many countries have established vehicle emission standards and regulations, greenhouse gas emissions stemming from urban transportation are still often above the levels that can be compensated in terms of social and environmental sustainability [2]. The idea of sustainability originates in the environmental movement that started drawing attention in the 1960s when urgent problems such as water and air pollution were surfacing in an increasing number of crowded urban areas. The term "sustainability" encompasses a holistic consideration of economic, social, and environmental progress with a longterm perspective in both a present (intra-generational) and future (inter-generational) context [3]. Sustainable mobility is a crucial issue, particularly in urban areas, making mobility more sustainable through translating into transport systems that are more accessible, efficient, safer, and climate responsive. According to the World Business Council for Sustainable Development [4], there are 7 goals proposed to improve the prospects for sustainable mobility: (1) reducing conventional emissions from transport so that they do not constitute a significant public health concern anywhere in the world, (2) limiting greenhouse gas emissions from transport to sustainable levels, (3) reducing significantly the number of transport-related deaths and injuries worldwide, (4) reducing transport-related noise, (5) mitigating traffic congestion, (6) narrowing "mobility divides" that exist within all countries and between the richest and poorest countries, and (7) improving mobility opportunities for the general population in developed and developing societies.

Sustainability requires setting targets and then measuring the distance to a target to get the appropriate information on the current state or trend [5]. Sustainability indicators refer to a policy-relevant variable defined in such a way as to be measurable over time and space [6]. They are not only useful for measuring progress but also for discovering problems, setting sustainable development goals, and identifying suitable management strategies [7][8]. Various indicators have been selectively grouped as indicator sets or aggregated as indices to provide assessment frameworks to comprehensively cover different aspects of environmental sustainability [9]. For example, Shane and Graedel determined 10 categories of urban environmental sustainability for the essential components of cities and a representative indicator for each category to evaluate the sustainability levels of cities [10]. Lima, da Silva Lima, and da Silva conducted a study that aims at the adjustment and application of a strategy to assess and select alternatives for improving the mobility conditions of a city by using the Index of Sustainable Urban Mobility (I_SUM) [11]. Moreover, Yigitcanlar and Dur introduced a sustainability assessment model used as an advanced geographic information system and an indicator-based 
comparative urban sustainability indexing model to assist planners and policy makers in sustainable urban planning and development [12]. Cavalcanti, Limont, Dziedzic, and Fernandes developed a methodology to assess the sustainability of urban mobility projects through an Urban Mobility Project Sustainability Index (UMPSI) associated with 17 sustainability indicators. Sustainability strategies inevitably require assessments of multi-factor multi-level decision-making [13]. During the last few decades, sustainability assessment has developed to be a structured procedure encompassing different field-specific analytical methods and models for specific applications and decision contexts [14].

Multi-criteria decision making (MCDM) techniques are commonly used to assess different kinds of sustainability indicators, and there are numerous MCDM methods based on different theoretical foundations, such as optimization, goal aspiration, outranking, or a combination of these. Ilgin, Gupta, and Battaiia presented a comprehensive review of the state of the art literature on the use of multi-criteria decision making techniques (MCDM) in the field of environmentally conscious manufacturing and product recovery [15]. They concluded that multi-criteria analysis is more popular than multi-objective optimization in this field, particularly the analytic hierarchy process (AHP)/analytical network process (ANP) and the technique for order preferences by similarity to ideal solutions (TOPSIS). It is suggested that linear aggregation models have problems of synergy or conflict among the different sustainability indicators and, therefore, non-compensatory MCDA approaches such as ELECTRE, PROMETHEE, and NAIDE are more appropriate [16]. In addition to conventional MCDM methods, fuzzy set theory has been recognized as a powerful technique to model systems that are difficult to define certainly and precisely. In recent years, fuzzy techniques have been frequently integrated into both the multicriteria analysis and multi-objective optimization methods for dealing with sustainability-related issues. Pavláková Docekalová, Doubravský, Dohnal, and Kocmanová indicated that corporate sustainability performance is usually highly nonlinear, vague, partially inconsistent and multidimensional, and thus the resulting models are often oversimplified [17]. They conducted evaluations of corporate sustainability indicators based on fuzzy similarity graphs. Egilmez, Gumus, and Kucukvar used expert-based fuzzy MCDA to assess the environmental sustainability of 27 U.S. and Canada cities [18], while Phillis, Kouikoglou, and Verdugo proposed a SAFE (sustainability assessment by fuzzy evaluation) model to evaluate the sustainability of cities [16]. Moreover, Pask, Lake, Yang, Tokos, and Sadhukhan developed a hybrid multicriteria approach using Fuzzy set theory and Monte Carlo simulation to evaluate the sustainability of alternative improvement options [19].

Sustainable urban mobility is a system that incorporates economic viability, environmental stability, and social equity by meeting the needs of transport and land use of both current and future generations in an efficient manner [20]. Improving urban sustainable mobility is a fundamental step to promote the global urban environment quality, also acting as an incentive for the social progress and economic growth. The development of guidance on sustainable urban mobility plans has raised considerable interest in recent years [21]. According to European Commission [22], sustainable urban mobility plans aim to create an urban transport system by addressing at least the following objectives: (1) ensuring all citizens who enjoy transport options that enable access to key destinations and services; (2) improving safety and security; (3) reducing air and noise pollution, greenhouse gas emissions, and energy consumption; (4) improving the efficiency and costeffectiveness of the transportation of persons and goods; and, (5) contributing to enhancing the attractiveness and quality of the urban environment and urban design for the benefits of citizens, the economy and society as a whole. To transform urban mobility effectively, it is necessary to conduct the assessments that are the result of a joint action between the different transport sectors, policy makers and relevant authorities at all levels. Within this context, this paper presents a fuzzy-based sustainability assessment approach for the promotion of sustainable urban mobility. This approach can be used to assist urban planners in assessing mobility alternatives and thus leading to more sustainable urban mobility.

\section{METHODS}

\section{A. Sustainability indicator}

Sustainability indicators effectively characterize various states of observed systems for decision makers to target and monitor environmental performance [23]. In practice, indicator sets and indices combining various sustainability dimensions or areas help decision makers to measure sustainability efforts on a much larger scale in comparison to the use of individual indicators [24]. They can be used to conduct an unbiased evaluation of sustainability performance to easily identify deficit areas requiring further improvement in urban mobility. Different practices use different indicators according to their particular needs, and these have been selected under different methods. However, while there are cases where urban sustainability indicators are effectively in use, the experiences gained from each practice have not been shared and used for the development of new urban development plans and for improving the decision-making process in the selection of indicators [25]. Responding to the necessity of sustainability assessment from a holistic view, sustainability indicators that cover multifaceted dimensions from economic, social, and environmental perspectives are defined as follows.

Economic indicator: The transport system should minimize infrastructure costs, reduce transport costs for access and mobility, and ensure long-term viability of the transport system.

Social indicator: The transport system can maintain human health and safety, meet the travel needs of the population, and enhance the attractiveness and quality of the urban landscape.

Environmental indicator: The transport system can reduce air and noise pollution, greenhouse gas emissions, and energy consumption. 
These sustainability indicators provide solid bases for decision-making at all levels and contribute to a sustainable urban mobility of integrating economic viability, environmental stability, and social equity. They are expressed in a hierarchical structure to indicate the level of the criteria for measurement as shown in Figure 1.

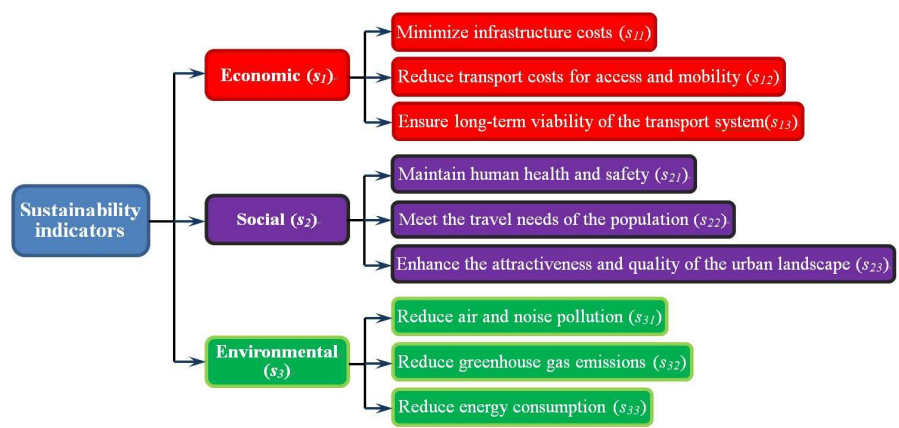

Fig. 1. A hierarchical structure of sustainability indicators for assessing sustainable urban mobility

\section{B. Aggregation operation with fuzzy numbers}

In order to aggregate the indicators into a performance index (PI), fuzzy measures based on Gaussian fuzzy numbers associated with the linguistic terms are used in this study. Fuzzy measures are typically monotonic set functions used to model either uncertainty or the strength of coalition of criteria in multi-criteria decision-making [26-28]. Let $A$ be a discrete fuzzy set (for the sustainability assessment) and $s_{t}$ be the subset of $\boldsymbol{\Lambda}$ (the sustainability indicators) that contains a finite number of elements $s_{i j}$ (the corresponding criteria). The aggregation, defined as the integration of a function (the data of elements to be aggregated) with respect to a fuzzy measure, can be formularized as

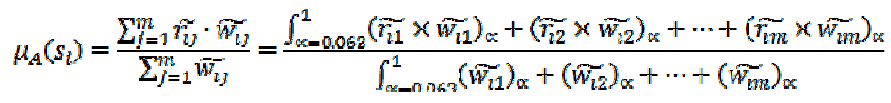

where

$\mu_{A}\left(s_{t}\right)$ represents the resultant membership function of the ith subset/indicator;

$\widetilde{r_{l j}}$ denotes the rating variable of the jth element/criterion of the ith subset/indicator; and,

$\widetilde{w_{l l}}$ is the weight variable of the jth element/criterion of the ith subset/indicator.

Fuzzy variables $\widetilde{r_{i j}}$ and $\widetilde{W_{t, j}}$ are fuzzy numbers. In this study, assessment was based on 7-point linguistic scales described by the continuous Gaussian membership functions (GMFs) $\left(\left(\mu_{A}(x)=e^{-\frac{1}{2}(x-c / v)^{2}}\right.\right.$, where $c$ is the center (i.e., mean), $\sigma$ is the width (i.e., standard deviation), and $2 \sigma 2=0.01$ ) shown in Figure 2. GMFs can be regarded as a normallydistributed ordered set of rating scales and are suitable for problems requiring continuously differentiable curves to capture the vagueness of rating responses. As the GMF is symmetric around its center value $c_{i}$, the fuzzy numbers are represented with interval notations (i.e., $\mathrm{VL}=[0,0.167], \mathrm{L}=[0$,
0.333], $\mathrm{ML}=[0.167,0.5], \mathrm{M}=[0.333,0.667], \mathrm{MH}=[0.5,0.833]$, $\mathrm{H}=[0.667,1]$, and $\mathrm{VH}=[0.833,1])$. The aggregation with continuous $\alpha$-cuts is a combination of extended algebraic operations based on interval arithmetic operations (addition, subtraction, multiplication, and division) and requires that every fuzzy number is represented by a continuous membership function and can be completely defined by its family of $\alpha$-cuts [29-31]. For $\widetilde{r}_{\alpha}-[a, b]$ and $\widetilde{w}_{c}-[c, d]$, the four arithmetic operations can be expressed as

- $(\tilde{r} \times \widetilde{w})_{\alpha}=\tilde{r}_{\alpha} \cdot \widetilde{w}_{\alpha}=[a, b] \cdot[c, d]=[\wedge(a c, a d, b c, b d), \vee(a c, a d, b c, b d)]=[e, f]=$ $\tilde{z}_{\alpha} ;$

- $\left(\widetilde{z_{1}}\right)_{\propto}+\left(\widetilde{z_{2}}\right)_{\propto}+\cdots+\left(\widetilde{z_{m}}\right)_{\propto}=\left[e_{1}, f_{1}\right]+\left[e_{2}, f_{2}\right]+\cdots+\left[e_{m}, f_{m}\right]=\left[\left(e_{1}+e_{2}+\cdots+\right.\right.$ $\left.\left.e_{m}\right),\left(f_{1}+f_{2}+\cdots+f_{m}\right)\right]=[\varepsilon, \eta]$

- $\left(\widetilde{w_{1}}\right)_{\propto}+\left(\widetilde{w_{2}}\right)_{\propto}+\cdots+\left(\widetilde{w_{m}}\right)_{\propto}=\left[c_{1}, d_{1}\right]+\left[c_{2}, d_{2}\right]+\cdots+\left[c_{m}, d_{m}\right]=\left[\left(c_{1}+c_{2}+\cdots+\right.\right.$ $\left.\left.c_{m}\right),\left(d_{1}+d_{2}+\cdots+d_{m}\right)\right]=[\rho, \sigma]$; and provided that $0 \notin[\rho, \sigma]$

- $\frac{[\varepsilon, \eta]}{[\rho, \sigma]}=[\varepsilon, \eta] \cdot\left[\frac{1}{\sigma}, \frac{1}{\rho}\right]=\left[\wedge\left(\frac{\varepsilon}{\rho}, \frac{\varepsilon}{\sigma}, \frac{\eta}{\rho}, \frac{\eta}{\sigma}\right), \mathrm{\vee}\left(\frac{\varepsilon}{\rho}, \frac{\varepsilon}{\sigma}, \frac{\eta}{\rho}, \frac{\eta}{\sigma}\right)\right]$

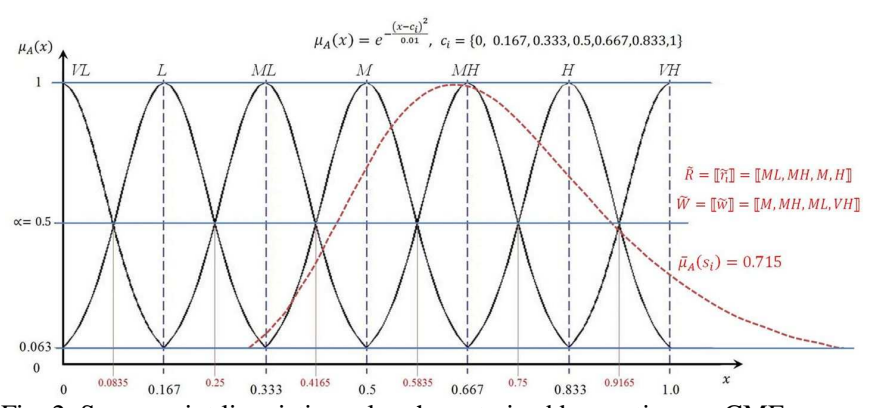

Fig. 2. Seven-point linguistic scales characterized by continuous GMFs

The result of the arithmetic operations is a crisp set (interval) that represents the $\alpha$-cut of the fuzzy set obtained by operating on fuzzy numbers $\widetilde{r}_{l j}$ and $\tilde{W}_{\imath \jmath}$. Through the aggregation operations, the family of $\alpha$-cuts defined as the resultant membership function of the measured subset/indicator can be presented as a convex and normalized fuzzy set, $s_{i}(x)$, which is also classified as a fuzzy number. Taking advantage of the center-of-gravity (COG) defuzzification method shown in Eq. (2), the quantitative value of the measured subset/indicator, $\bar{\mu}_{A}\left(s_{i}\right)$, can be derived. These defuzzified fuzzy numbers must be mapped into $(0,1)$ intervals (i.e., $\left.\hat{\mu}_{A}: X \rightarrow(0,1)\right)$ in order to obtain a set of quantitative values representing the derived membership grades, $\hat{\mu}_{A}\left(s_{i}\right)$, for the fuzzy measure operations. An example of the linguistic aggregation and defuzzification result is also shown in Figure 2.

$$
\bar{\mu}_{A}\left(s_{i}\right)=\frac{\int_{g}^{h} s_{t}(x) \cdot x d x}{\int_{g}^{h} s_{i}(x) d x}
$$

where

$s_{i}(x)$ represents the resultant fuzzy number of the measured subset/indicator i; and,

$g$ and $h$ are the respective lower and upper limits of the support of the fuzzy number. 


\section{Performance index}

An $\sigma$-algebra over a set $A$ is an algebra closed under countable unions. Let $A$ be a non-empty set and $u_{i}$ a $\sigma$-algebra defined on $A$. A fuzzy measure $m$ defined on the measurable space $\left(\Lambda, u_{l}\right)$ is a set function $m: u_{l} \rightarrow[0, \infty)$ which verifies the following axioms: (1) $m(\varnothing)-0$; and (2) $u_{1}, u_{2} \in u_{t}, u_{1} \subseteq u_{2} \Rightarrow m\left(u_{1}\right) \leq m\left(u_{2}\right)$ [32]. Based on the $\sigma$-additive set function, the performance index (PI) is defined as the fuzzy measure of $A$, which can be expressed as

$$
P I=m(A)=\bigcup_{i=1}^{n} s_{i}=\sum_{i=1}^{n} a_{A}\left(s_{i}\right)
$$

where

$\hat{\mu}_{A}\left(s_{i}\right)$ is the membership grade value, indicating the degree of evidence or belief that subset/indicator $s_{i}$ belongs to $A$ in $X$.

By substituting the corresponding membership grade values into Eq. (3), the performance indexes (PIs) of the measured alternatives can be derived; the higher the PI value, the more desirable the evaluated alternative is.

\section{RESULTS}

Transport systems exist to provide social and economic connections, and people quickly take up the opportunities offered by increased mobility [33]. However, the advantages of increased mobility need to be weighed against the environmental, social, and economic costs that transport systems pose. Sustainable transport systems make a positive contribution to the environmental, social, and economic sustainability of the communities they serve. This section presents a case study to demonstrate the applicability of the proposed approach. The case study focuses on the sustainability assessment of alternatives for urban transportation systems.

\section{A. Description of the target city}

Kaohsiung City sits on the southwestern coast of Taiwan facing the Taiwan Strait, which is the largest harbor city in Taiwan covering an area of 2,952 square kilometers with a population of approximately 2.77 million. In addition to the harbor and the international airport, Kaohsiung City is the southern terminal of the Freeway 1 and is served by the Taiwan Railways Administration (TRA) stations of TRA Western Line and Pingtung Line. The Taiwan High Speed Rail also provides fast and frequent railway connection to Taipei-the capital city of Taiwan.

Over the last decade, Kaohsiung has shifted strategically from a petrochemical and heavy industry city with high levels of industrial pollution into a city promoting an environmentally friendly lifestyle. To further improve urban transport and air pollution problems, the Kaohsiung Mass Rapid Transit (Kaohsiung MRT) was launched for revenue service in early 2008. The construction of Circular Light Rail Line (Kaohsiung LRT) also began in 2013, and is scheduled to be in full operation by mid-2017 (see Figure 3). Phase II construction of Kaohsiung LRT will start after the Kaohsiung urban railway is relocated underground in 2017. It is scheduled to be completed in 2019. In the near future,
Kaohsiung intends to become an eco-friendly city whose ultimate goal is to reduce carbon waste, produce energy entirely through renewable resources, and merge the city harmoniously with the natural environment.

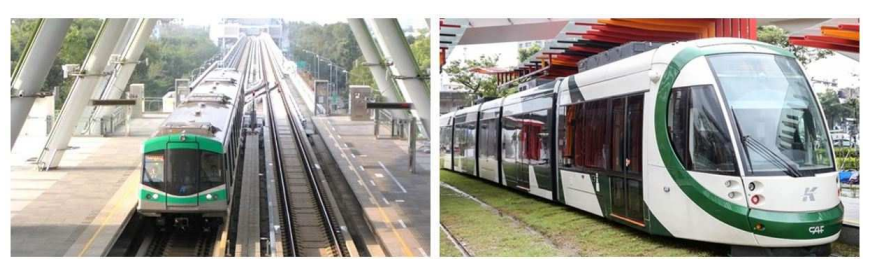

Fig. 3. Kaohsiung MRT (left) and Kaohsiung LRT (right)

\section{B. Alternatives}

Public transportation is a shared passenger-transport service which is available for use by the general public and provides personal mobility. Urban public transport modes can be divided into five groups, namely paratransit, bus, light rail transit (LRT), suburban rail, and rapid rail transit (RRT). In recent years, shared-use vehicle systems have generated increased interest and enthusiasm as an innovative mobility solution in urban areas. The basic premise of shared-use vehicles is to move away from individual vehicle ownership exclusively; instead, a fleet of vehicles can be shared throughout the day by different users to provide an additional mobility option [34]. In this study, three shared-use vehicle systems (bike sharing system, electric bike sharing system, and electric car sharing system) were selected as alternatives for the sustainability assessment as listed in Table 1.

TABle 1. Alternatives OF SHARED-USE VEHICLE SYSTEMS FOR THE SUSTAINABILITY ASSESSMENT

\begin{tabular}{|c|c|c|}
\hline Alternative 1 & Alternative 2 & Alternative 3 \\
\hline Bike sharing system & e-bike sharing system & e-car sharing system \\
\hline जिन शhulf & & \\
\hline
\end{tabular}

\section{Sustainability assessment for the selected alternatives}

According to the sustainability indicators shown in Figure 1, the evaluators evaluated the alternatives and determined the weights of the criteria. The evaluation grades are a 7-point linguistic scale, ranging from $\mathrm{VH}$ (very high agreement/importance) to VL (very low agreement/importance). The ratings and weights were derived as the two sets shown in Table 2, where $\tilde{r}_{l j}$ and $\overline{w_{l j}}$ are linguistic variables as defined above.

TABLE 2. LIST OF THE DERIVED LINGUISTIC VARIABLES OF RATINGS AND WEIGHTS

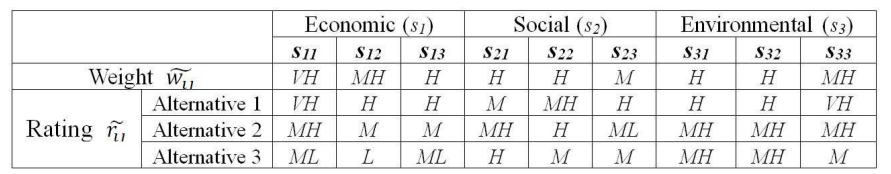


By substituting the corresponding fuzzy numbers of the rating and weight variables into Eq. (1) to perform the aggregation operations, the resultant membership functions and their corresponding defuzzified fuzzy numbers were derived. Then, the quantitative values of the membership grades, $\hat{\mu}_{A}\left(s_{t}\right)$, and the performance index PI corresponding to each alternative were obtained as shown in Table 3.

TABle 3. PERFormance IndEX CORRESPONDING TO THE SELECTED ALTERNATIVES

\begin{tabular}{|c|c|c|c|c|c|}
\hline & $\hat{\mu}_{A}\left(s_{1}\right)$ & $\hat{\mu}_{A}\left(s_{2}\right)$ & $\hat{\mu}_{A}\left(s_{3}\right)$ & $P I$ & Ranking \\
\hline Alternative 1 & 0.925 & 0.714 & 0.935 & 2.574 & 1 \\
\hline Alternative 2 & 0.608 & 0.726 & 0.732 & 2.066 & 2 \\
\hline Alternative 3 & 0.324 & 0.700 & 0.683 & 1.707 & 3 \\
\hline
\end{tabular}

According to the sustainability assessment results, the best shared-use vehicle system for sustainable urban mobility is Alternative 1 and the worst is Alternative 3. Bike-sharing is a model of cost-effectiveness both for users and cities. Using bike share to commute is cheaper than public transit for system members. At present, the bicycle is one of the most common transport modes which provides affordable access for short-distance trips in an urban area. If cycling facilities are provided at the right places and designed in an appropriate manner for each type of city, people will more likely decide to use them on daily bases [35-38]. In fact, Kaohsiung is the most bike-friendly city in Taiwan and it has a growing network of bike lanes that currently adds up to 150 kilometers.

\section{A modified shared-use vehicle system}

To improve sustainable urban mobility, we proposed a modified bike-sharing system named "Power Bike", which is a service network of bicycle rental kiosks for Kaohsiung City. The Power Bike is an excellent way to get around the Kaohsiung City, complementing the MRT, LRT, and public bus systems and giving users the option of conveniently renting a bicycle to explore the city. As shown in Figure 4, each bike provides an in-vehicle GPS receiver for riders to pinpoint their speed and position on the map and to follow a route to reach their destination. Moreover, it is also equipped with a bicycle dynamo system to generate electricity for its LED lighting and GPS receiver. The residual electricity can be recharged back into the stand for the rental station use when replacing the bike in any stations, by which the rider can be rewarded with feedback money through his/her prepaid member card (iPASS). The features of the modified bike-

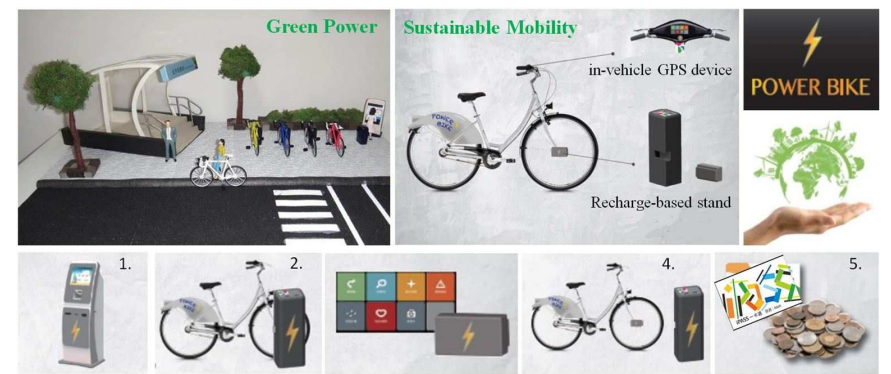

sharing system are as follows:

Fig. 4. Features of the modified bike-sharing system-"Power Bike"
1. The kiosk for displaying information such as instructions, charges, membership, and other details of the rental station.

2. Using the registered contactless smartcard (iPASS) to unlock and remove the bike.

3. Equipped with a bicycle dynamo system to generate electricity for the GPS receiver.

4. Recharging back the residual electricity into the stand when replacing the bike.

5. Rewarded with feedback money through the iPASS after returning the bike to the rental station.

\section{CONCLUDING REMARK}

For the past several decades, transport and mobility have been a crucial part of our economy and our society while conducting a vital role for both the internal market and the quality of life of citizens. However, the dominant dependency of urban mobility has dramatically increased the burden on the society and environment. In recent years, the idea of sustainable urban mobility has raised considerable interest in which the promotion of sustainable urban mobility is a determinant factor in a sustainable urban development. In order to make significant improvements and decisions, it is necessary to operate a flexible and sufficient sustainability assessment for prompting urban mobility.

Fuzzy techniques have been frequently integrated into multi-criteria decision analysis and multi-objective optimization methods for dealing with sustainability-related issues. This paper presents a fuzzy-based sustainability assessment approach for the promotion of sustainable urban mobility. In the approach, a hierarchical structure of sustainability indicators was proposed, which provides solid bases for decision-making at all levels of integrating economic viability, environmental stability, and social equity. Fuzzy measures based on Gaussian fuzzy numbers associated with 7point linguistic terms were used to aggregate the indicators into a performance index. To demonstrate the applicability of the proposed approach, a case study concerning the sustainability assessment of alternatives for urban transport systems was conducted. A modified bike-sharing system named "Power Bike" was further proposed, which is a service network of bicycle rental kiosks for Kaohsiung City.

\section{Acknowledgment}

This research was financially supported by I-Shou University under grant number ISU-106-01-09A. The author would also like to thank Mr. Wei-Jun Chou for his assistance in the modified bike-sharing system design of the case study.

\section{References}

[1] R.B. Hiremath, P. Balachandra, B. Kumar, S.S. Bansode, and J. Murali, "Indicator-based Urban Sustainability-A Review," Energy for Sustainable Development, vol. 17 (6), pp. 555-563, 2013.

[2] P. Baer, J. Harte, B. Haya, A.V. Herzog, J. Holdren, N.E. Hultman, D.M. Kammen, R.B. Norgaard, and L. Raymond, "Climate change: 
Equity and greenhouse gas responsibility," Science, vol. 289 (5488), pp. 2287,2000

[3] J. Zietsman, T. Ramani, J. Potter, V. Reeder, and J. DeFlorio, NCHRP Report 708: A Guidebook for Sustainability Performance Measures for Transportation Agencies. Washington, D.C.: Transportation Research Board of the National Academies, 2011. http://www.trb.org/Publications/Blurbs/166313.aspx.

[4] World Business Council for Sustainable Development (WBCSD), Mobility 2030: Meeting the challenges to sustainability. The Sustainable Mobility Project. Executive Summary 2004, 5, 6, 2004.

[5] B. Moldan, S. Janoušková, and T. Hák, "How to understand and measure environmental sustainability: Indicators and targets," Ecological Indicators, vol. 17, pp. 4-13, 2012.

[6] F. Astleithner, A. Hamedinger, N. Holman, and Y. Rydin, "Institutions and Indicators-the discourse about indicators in the context of sustainability," Journal of Housing and the Built Environment, vol. 19 (1), pp. 7-24, 2004.

[7] M.S. Reed, E.D. Fraser, and A.J. Dougill, "An adaptive learning process for developing and applying sustainability indicators with local communities," Ecological Economics, vol. 59 (4), pp. 406-418, 2006.

[8] U. Pupphachai and C. Zuidema, "Sustainability indicators: A tool to generate learning and adaptation in sustainable urban development," Ecological Indicators, vol. 72, pp. 784-79, 2017.

[9] R.K. Singh, H.R. Murty, S.K. Gupta, and A.K. Dikshit, "An overview of sustainability assessment methodologies,” Ecological Indicators, vol. 15 (1), pp. 281-299, 2012.

[10] A.M. Shane and T.E. Graedel, "Urban environmental sustainability metrics: a provisional set," Journal of Environmental Planning and Management, vol. 43 (5), pp. 643-663, 2000.

[11] J.P. Lima, R. da Silva Lima, and A.N.R. da Silva, "Evaluation and selection of alternatives for the promotion of sustainable urban mobility," Procedia-Social and Behavioral Sciences, vol. 162, pp. 408418, 2014.

[12] T. Yigitcanlar and F. Dur, "Developing a sustainability assessment model: The sustainable infrastructure, land-use, environment and transport model," Sustainability, vol. 2, pp. 321-340, 2010.

[13] C.d.O. Cavalcanti, M. Limont, M. Dziedzic, and V. Fernandes, "Sustainability assessment methodology of urban mobility projects," Land Use Policy, vol. 60, pp. 334-342, 2017.

[14] S. Sala, B. Ciuffo, and P. Nijkamp, "A systemic framework for sustainability assessment," Ecological Economics, vol. 119, pp. 314325, 2015.

[15] M.A. Ilgin, S.M. Gupta, and O. Battaïa, "Use of MCDM techniques in environmentally conscious manufacturing and product recovery: State of the art," Journal of Manufacturing Systems, vol. 37 (3), pp. 746-785, 2015.

[16] Y.A. Phillis, V.S. Kouikoglou, and C. Verdugo, "Urban sustainability assessment and ranking of cities," Computers, Environment and Urban Systems, vol. 64, pp. 254-265, 2017.

[17] M. Pavláková Docekalová, K. Doubravský, M. Dohnal, and A. Kocmanová, "Evaluations of corporate sustainability indicators based on fuzzy similarity graphs," Ecological Indicators, vol. 78, pp. 108-114, 2017.

[18] G. Egilmez, S. Gumus, and M. Kucukvar, Environmental sustainability benchmarking of the US and Canada metropoles: An expert judgmentbased multicriteria decision making approach," Cities, vol. 42, pp. 3141, 2015.

[19] F. Pask, P. Lake, A. Yang, H. Tokos, and J. Sadhukhan, "Sustainability indicators for industrial ovens and assessment using Fuzzy set theory and Monte Carlo simulation," Journal of Cleaner Production, vol. 140, pp. 1217-1225, 2017.

[20] P. Kayal, R. Singh, and M. Kumar, "Defining Sustainable Urban Mobility," TERI-NFA Working paper No. (11), The Energy and Resources Institute, 2014.

[21] A.D. May, "Encouraging good practice in the development of Sustainable Urban Mobility Plans," Case Studies on Transport Policy, vol. 3, pp. 3-11, 2015.

[22] European Commission, "Guidelines-Developing and implementing a sustainable urban mobility plan," Brussels: Directorate-General for Mobility and Transport, 2013.

[23] C. Jasch, "Environmental performance evaluation and indicators," Journal of Cleaner Production, vol. 8, pp. 79-88, 2000.

[24] C.B. Joung, J. Carrell, P. Sarkar, and S.C. Feng, "Categorization of indicators for sustainable manufacturing," Ecological Indicators, vol. 24, pp. 148-157, 2013.

[25] L.Y. Shen, J.J. Ochoa, M.N. Shah, and X.L. Zhang, "The application of urban sustainability indicators-A comparison between various practices," Habitat International, vol. 35 (1), pp. 17-29, 2011.

[26] I. Kojadinovic, "Modelling interaction phenomena using fuzzy measures: on the notions of interaction and independence," Fuzzy sets and Systems, vol. 135, pp. 317-340, 2003.

[27] A. Wagholikar and P. Deer, "Fuzzy measures acquisition methods," Engineering Letters, vol. 14 (2), pp. 56-60, 2007.

[28] R.R. Yager, "Uncertainty modeling using fuzzy measures," KnowledgeBased Systems, vol. 92, pp. 1-8, 2016.

[29] L.A. Zadeh, "The concept of linguistic variable and its application to approximate reasoning," parts 1-2, Information Sciences, vol. 8, 199249, pp. 301-357, 1975.

[30] L.A. Zadeh, "The concept of linguistic variable and its application to approximate reasoning," parts 3, Information Sciences, vol. 9, pp. 43-80, 1976.

[31] G.J. Klir and B. Yuan, Fuzzy Sets and Fuzzy logic: Theory and Applications, Prentice-Hall International, Inc., NJ: Englewood Cliffs, 1995.

[32] P.R. Halmos, Measure theory, Springer-Verlag, Inc., NY: HeidelbergBerlin, 1974.

[33] A. Schafer, "The global demand for motorized mobility," Transportation Research A, vol. 32 (6), pp. 455-477, 1998.

[34] M. Barth and S.A., Shaheen, "Shared-use vehicle systems: Framework for classifying carsharing, station cars, and combined approaches," Transportation Research Record: Journal of the Transportation Research Board, vol. 1791, pp. 105-112, 2002.

[35] N.Y. Tilahun, D.M. Levinson, and K.J. Krizek, "Trails, lanes, or traffic: valuing bicycle facilities with an adaptive stated preference survey," Transportation Research, vol. 41A, pp. 287-301, 2007.

[36] M. Winters, G. Davidson, D. Kao, and K. Teschke, "Motivators and deterrents of bicycling: comparing influences on decisions to ride," Transportation, vol. 38, pp. 153-168, 2011.

[37] S. Flugel, F. Ramjerdi, K. Veisten, M. Killi, and R. Elvik, "Valuation of cycling facilities with and without risk controlling for casualty risk," International Journal of Sustainable Transportation, vol. 9, pp. 364-376, 2015 .

[38] M. Kamargianni, "Investigating next generation's cycling ridership to promote sustainable mobility in different types of cities," Research in Transportation Economics, vol. 53, pp. 45-55, 2015. 